\title{
ИСПОЛЬЗОВАНИЕ ПОРОШКА ИЗ ЯГОД ИРГИ В КАЧЕСТВЕ ЗАМЕНИТЕЛЯ САХАРА В ПРОИЗВОДСТВЕ МУЧНЫХ КОНДИТЕРСКИХ ИЗДЕЛИЙ
}

\author{
L.G. Ermosh, N.V. Prisukhina, V.V. Kazina
}

\section{USING THE POWDER OF MESPILUS BERRIES AS SUGAR SUBSTITUTE IN FLOUR CONFECTIONERY PRODUCTION}

Ермош Л.Г. - д-р техн. наук, проф. каф. технологий хлебопекарного, кондитерского и макаронных производств Красноярского государственного аграрного университета, г. Красноярск. E-mail: 2921220@mail.ru

Присухина Н.В. - канд. техн. наук, доц. каф. технологий хлебопекарного, кондитерского и макаронных производств Красноярского государственного аграрного университета, г. Красноярск. E-mail: nat3701@mail.ru

Казина В.В. - инженер-технолог Центра здорового питания Торгово-экономического института Сибирского федерального университета, г. Красноярск. E-mail: v.mutovina89@yandex.ru

Дикорастущие и культивируемые плоды и ягоды Сибири и Дальнего Востока, благодаря своему разнообразному химическому составу, имеют большое значение для предприятий пищевых производств. Немаловажный интерес представляет ирга круглолистная (лат. Amelanchier rotundi folia) - вид рода Ирга (лат. Amelanchier), подсемейства Яблоневые (лат. Maloideae), семейства Розовые (лат. Rosaceae). Химический состав плодов ирги достаточно хорошо исследован. Доказано, что плоды являются источником многих биологически активных веществ: сахара, органические кислоты, антоцианы, фллавоноиды, пищевые волокна, витамины группы $B, C, P$, $\beta$-каротин и микроэлементы. В семенах содержится масло. Кора и листья ирги богаты дубильными веществами. При отжиме сока из ягод ирги образуются выжимки, из которых получают порошок, обладающий сладким вкусом, ярким иветом и достаточно высокой пищевой ценностью. Однако ассортимент продуктов, обогащенных порошком из плодов ирги, крайне ограничен. Цель работы - исследо-
Ermosh L.G. - Cand. Techn. Sci., Prof., Chair of Technologies of Baking, Confectionery and Macaroni Productions, Krasnoyarsk State Agrarian University, Krasnoyarsk.

E-mail:2921220@mail.ru

Prisukhina N.V. - Cand. Techn. Sci., Assoc. Prof., Chair of Technologies of Baking, Confectionery and Macaroni Productions, Krasnoyarsk State Agrarian University, Krasnoyarsk.

E-mail: nat3701@mail.ru

Kazina V.V. - Engineer-Technologist, Healthy Food Center, Trade and Economic Institute, Siberian Federal University, Krasnoyarsk.

E-mail: v.mutovina89@yandex.ru

вать возможность использования порошка из ягод ирги в качестве заменителя сахара в бисквитных полуфабрикатах. Объектами исследования являлись порошок из ягод ирги, бисквитное тесто с различным содержанием порошка и готовые изделия. Порошок ирги был получен конвективным способом высушивания из вьжимок. В работе приведены результаты исследований по формированию органолептических, фризико-химических и структурномеханических показателей бисквитов с заменой от 25 до $50 \%$ сахара на порошок из плодов ирги. Установлено, что замена 25 и 30 \% сахара на порошок положительно влияет на объем и стабильность яично-сахарной массы, формирует высокие органолептические показатели, необходимые структурно-механические показатели готового бисквита. Обоснована микробиологическая безопасность новых видов бисквитов на протяжении срока хранения. Полученные результаты дают основание для использования порошка из плодов ирги в качестве натурального заменителя 30 \% сахара. Это позволяет снизить калорийность 
бисквитного изделия по сравнению с традиционным, повысить пищевую ценность за счет введения в рецептурный состав минеральных веществ и витаминов, сформировать новые вкусовые качества бисквитов.

Ключевье слова: порошок из плодов ирги, пищевая ценность, органолептические показатели, бисквит, заменитель сахара, активHость воды.

Wild-growing and cultivated fruits and berries of Siberia and the Far East, thanks to various chemical composition are of great importance for the enterprises of food production. Great interest is represented for mespilus round-leaved (Latin Amelanchier rotundi folia), the type of the sort Mespilus (Latin of Amelanchier), subfamilies Appletree (Latin Maloideae), families Pink (Latin Rosaceae). Chemical composition of fruits of mespilus is rather well investigated. It is proved that they are the source of many biologically active agents: sugar, organic acids, antotsiana, flavonoids, food fibers, vitamins of group $B, C, P$, $\beta$-carotin and microcells. The seeds contain oil. Bark and leaves of mespilus are rich in tannins. At juice extraction the residues from receiving the powder possessing sweet taste, bright color and rather high nutrition value are formed of berries of mespilus. However, the range of the products enriched with powder from mespilus fruits is extremely limited. The work purpose was to investigate the possibility of using the powder from mespilus berries as sugar substitute in biscuit semi-finished products. The objects of the research were the powder from mespilus berries, egg sponge with various content of powder and finished products. The powder of mespilus was received by convective way of drying from the residue. The results of the researches on the formation of organoleptic, physical and chemical, structural and mechanical indicators of biscuits with the replacement from 25 to $50 \%$ of sugar for powder from mespilus fruits were given in the study. It was established that the replacement of 25 and $30 \%$ of sugar by powder positively influenced the volume and stability of egg and sugar weight, formed high organoleptic rates, necessary structural and mechanical indicators of a ready biscuit. Microbiological safety of new types of biscuits throughout the period of storage was justified. Received results give the grounds for using the powder from mespilus fruits as natural substitute of $30 \%$ of sugar. It allows to reduce caloric content of a biscuit product in comparison with traditional, to raise nutrition value due to introduction to the prescription structure of mineral substances and vitamins, to create new tastes of biscuits.

Keywords: mespilus fruits powder, nutrition value, organoleptic indicators, a biscuit, sugar substitute, activity of water.

Введение. Значительные площади культурных насаждений ирги круглолистной (лат. Amelanchier rotundi folia) - вида рода Ирга (лат. Amelanchier), подсемейства Яблоневые (лат. Maloideae), семейства Розовые (лат. Rosaceae) в плодопитомнических совхозах, садах по всей стране получают стабильно высокие урожаи, что способствует увеличению объемов продовольственного сырья. Однако плоды ирги мало используют в качестве сырья в пищевой промышленности из-за отсутствия нормативной документации на свежие плоды и научно обоснованных рекомендаций по ее использованию и других фракторов [1].

Плоды ирги употребляются в пищу свежими, перерабатываются на варенье, пастилу, желе, вино, желейно-мармеладные изделия [2]. Низкое содержание влаги в плодах позволяет их быстро сушить и использовать для витаминных напитков с ярко выраженным цветом.

Высокий процент отходов, образующихся в производстве сока из плодов ирги (в среднем 20-25\% от массы плодов), служит базой для получения порошка из выжимок с выраженным сладким вкусом и насыщенным темнофиолетовым цветом, который используется в качестве наполнителя в различных видах продуктов питания.

Одним из направлений применения ягодных и плодовых порошков являются мучные кондитерские изделия. Большим спросом у потребителя различных возрастных категорий пользуются бисквитные изделия как с кремовыми наполнителями (торты, пирожные), так и самостоятельные изделия (сухие, влажные бисквиты). Традиционные бисквиты содержат неприемлемо большое для современного питания количество сахара (35 \% от массы изделия), обладают высокой калорийностью, низким содержанием витаминов, пищевых волокон. По- 
этому вопрос обогащения их состава за счет различных добавок, снижения калорийности, повышения пищевой ценности решается различными способами. Научные исследования доказывают положительное влияние различных видов ягодных, плодовых наполнителей на качественные показатели бисквитного теста и пищевую ценность готовых изделий $[3,4]$.

Цель работы. Исследовать возможность использования порошка из ягод ирги в качестве заменителя сахара в бисквитных полусаарикатах.

Задачи: определить углеводный потенциал порошка ирги, исследовать влияние порошка на структурно-механические показатели бисквитного теста, готовых изделий, формирование органолептических характеристик, сроки годности.

Объекты и методы исследований. Объектами исследования являлись: порошок из ягод ирги, бисквитное тесто с его использованием и готовые изделия. Порошок ирги был получен конвективным способом высушивания выжимок. Необходимые для работы показатели химического состава порошка определяли стандартными методами. Разработку рецептур проводили с заменой части сахара на порошок из ирги от 25 до $50 \%$. В качестве контрольного служил образец бисквита классического [5]. Порошок ирги соединяли с сахаром и вводили при взбивании яичной массы. Качественные характеристики яично-сахарной массы контрольного образца и с порошком определяли по объему пены и ее стабильности во времени - через 6 часов. Качество бисквитного теста определяли по объему и плотности. У готовых изделий анализировали такие показатели, как влажность, пористость, намокаемость. В работе применяли общепринятые методы исследований. Органолептическую оценку выпеченных изделий проводили по 10-балльной шкале. В качестве экспресс-метода определения микробиологической безопасности бисквитов в процессе хранения использовали гигрометр RotonicHygroPalmHP23AW-Set - прибор для определения активности воды. Обработку статистических данных проводили с использованием пакета прикладных программ «Statistica 6.0». При сравнении средних значений разница считалась достоверной при 95\%-м уровне значимости $(p<0,05)$.

Результаты исследований и их обсуждение. Полученный порошок из ягод ирги представляет собой мелкодисперсную массу с ярким цветом, насыщенным ароматом, интенсивно сладким вкусом. Химический состав порошка из ягод ирги приведен в таблице.

\section{Химический состав порошка из ягод ирги $(M \pm m)(n=6)$}

\begin{tabular}{|l|c|}
\hline \multicolumn{1}{|c|}{ Показатель } & Содержание в 100 г порошка \\
\hline Массовая доля влаги, \% & $7,54 \pm 0,04$ \\
\hline Массовая доля углеводов, \% & $53,11 \pm 0,43$ \\
\hline В т.ч.: моно- и дисахариды & $29,33 \pm 0,11$ \\
\hline \multicolumn{1}{|c|}{ - пектиновые вещества } & $6,15 \pm 0,05$ \\
\hline \multicolumn{1}{|c|}{ - клетчатка } & $5,62 \pm 0,04$ \\
\hline Органические кислоты & $2,91 \pm 0,09$ \\
\hline Кальций мг & $24,22 \pm 0,42$ \\
\hline Магний мг & $23,87 \pm 0,25$ \\
\hline Железо мг & $7,39 \pm 0,1$ \\
\hline Витамин С, мг & $56,33 \pm 0,11$ \\
\hline Витамин В 1 ( тиамин), мг & $1,16 \pm 0,06$ \\
\hline Витамин В (рибосрлавин), мг & $1,33 \pm 0,07$ \\
\hline Витамин В6 (пиридоксин), мг & $1,48 \pm 0,12$ \\
\hline
\end{tabular}


Из таблицы видно, что порошок имеет высокое содержание моно- и дисахаридов, формирующих сладкий вкус, в том числе и будущего продукта.

Исследовали влияние порошка на объем яичносахарной массы и стабильность пены (рис. 1, 2).

Порошок ирги до 30 \% (от массы сахара) способствует пенообразованию яично-сахарной массы. Однако дальнейшая замена сахара снижает процесс пенообразования. Аналогичные результаты наблюдаются при анализе стабильности пенной массы во времени. Известно, что сахар является стабилизатором пенной массы.

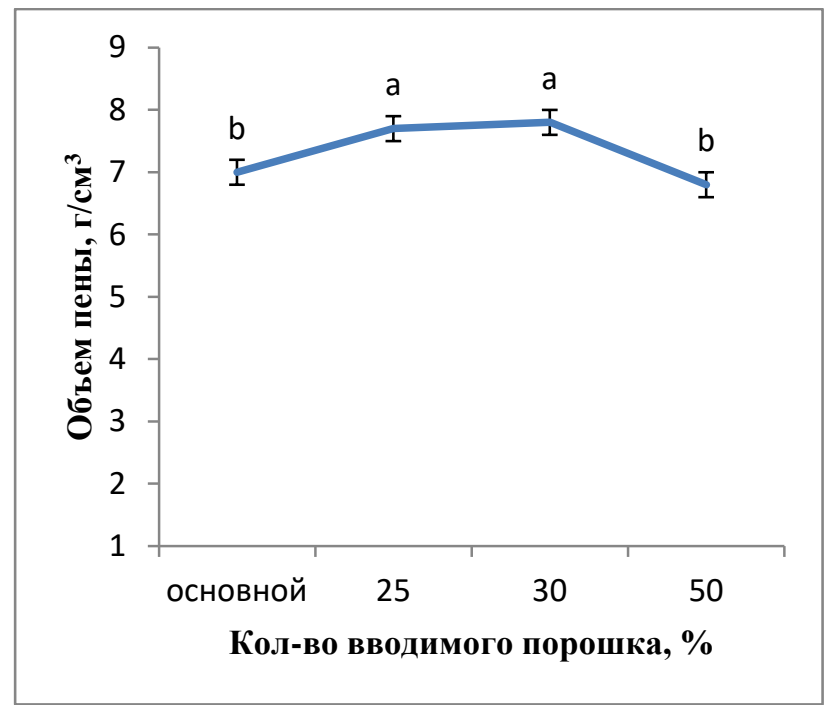

Puc. 1. Динамика изменения объема яично-сахарной массы с порошком ирги. Здесь и далее: буквами обозначены межгрупповые различия, $p<0,05$

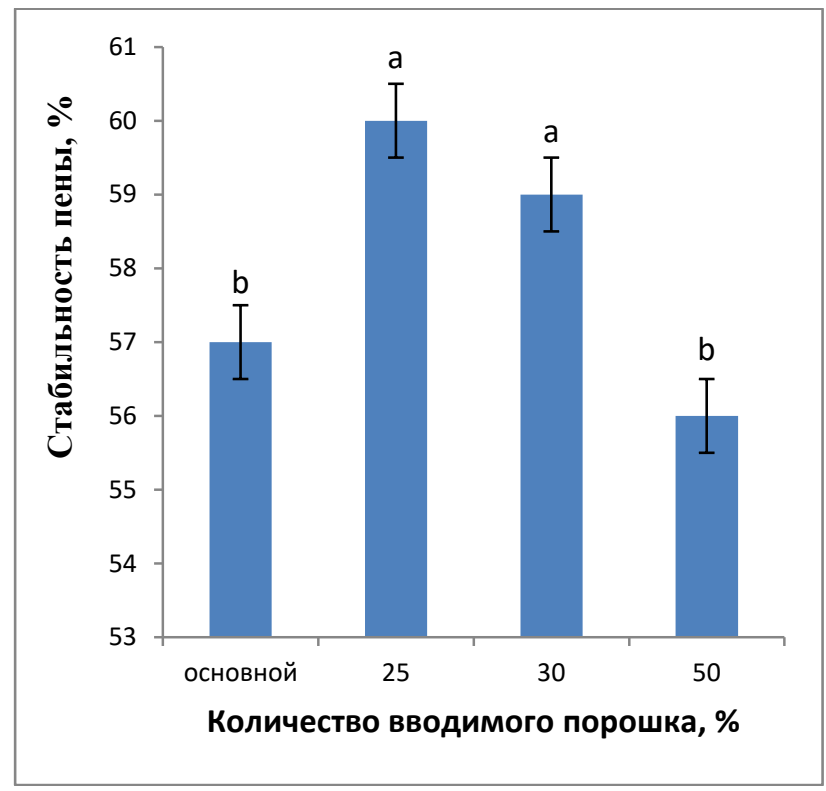

Puc. 2. Влияние порошка ирги на стабильность яично-сахарной массы

Повышение стабильности пены с порошком во времени (6 часов) связано со значительным содержанием не только моносахаридов в порошке, но и пектиновых веществ, которые, как известно, являются стабилизаторами пенных масс [3].
На рисунках 3, 4 представлены изменения массы и массовой доли влаги в выпеченных бисквитах. 


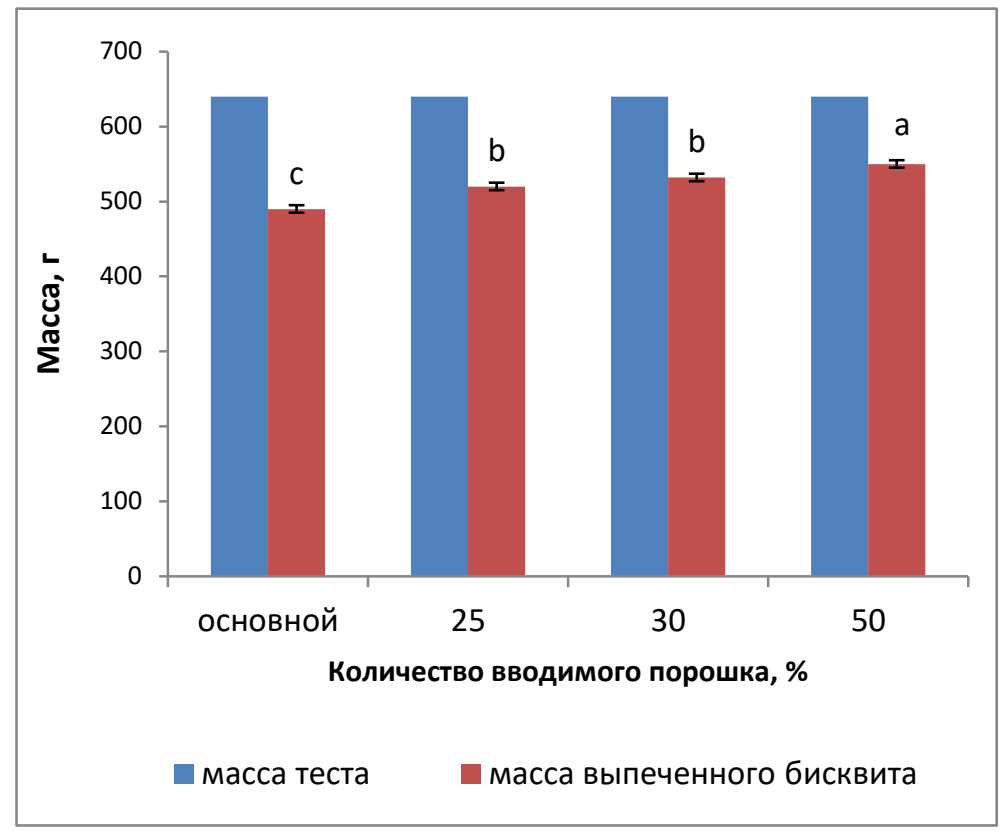

Puс. 3. Изменение массы выпеченных бисквитов при введении порошка ирги

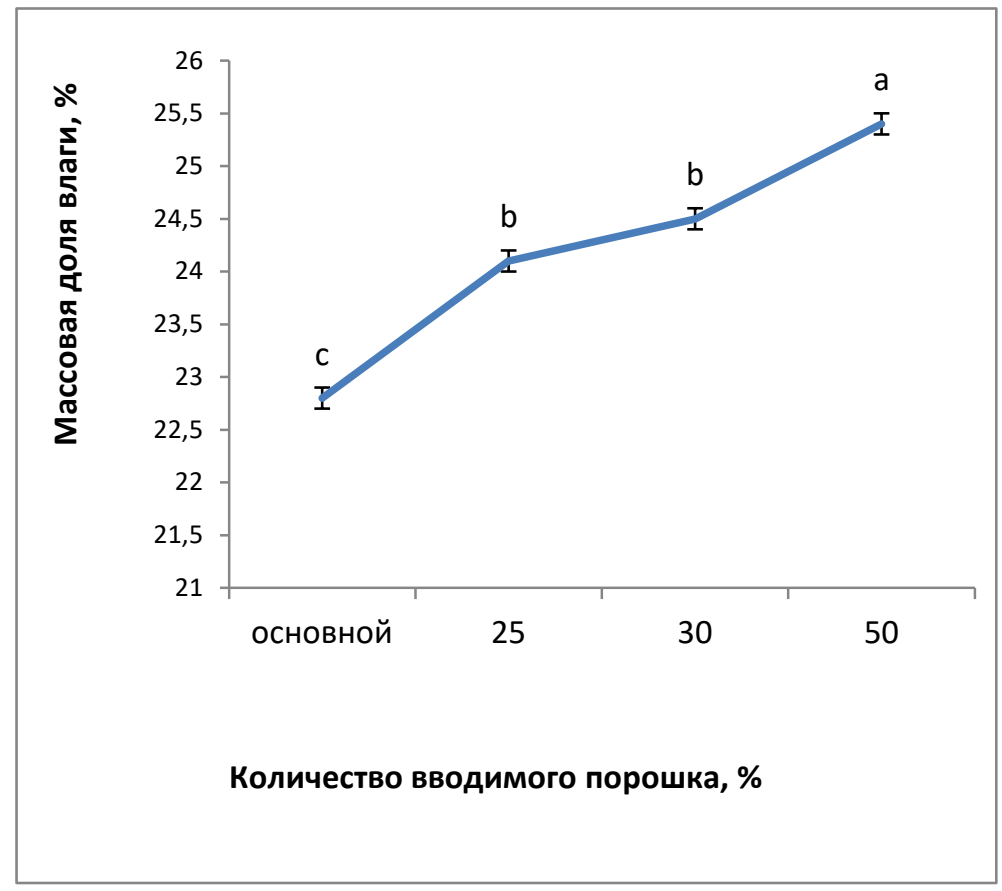

Puc. 4. Изменение массовой доли влаги выпеченных бисквитов при введении порошка ирги

Исследования показали влияние порошка на сохранность массы готовых изделий. Замена $50 \%$ сахара на порошок ирги приводит к повышению сохранности массы на 7,4 \% по сравнению с контрольным образцом. При этом повышается влажность готовых изделий, однако их значения соответствуют нормируемым показа-

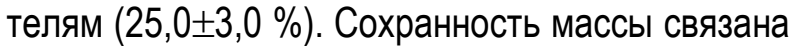
с введением в систему пектиновых веществ, клетчатки, обладающих гидроколлоидными свойствами [3].

На рисунках 5, 6 представлено изменение пористости и намокаемости готовых бисквитов с введением в их состав порошка ирги. 


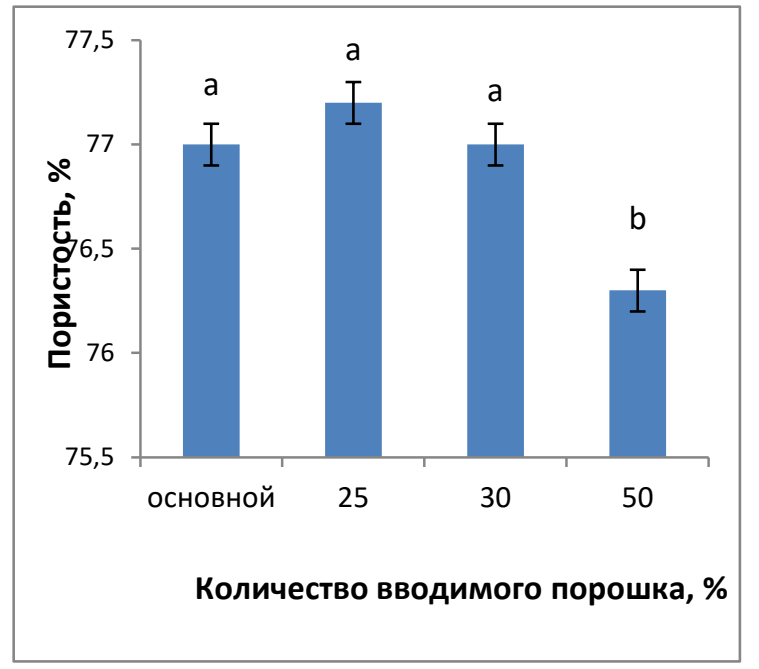

Pис. 5. Изменение пористости готовых бисквитов при введении порошка ирги

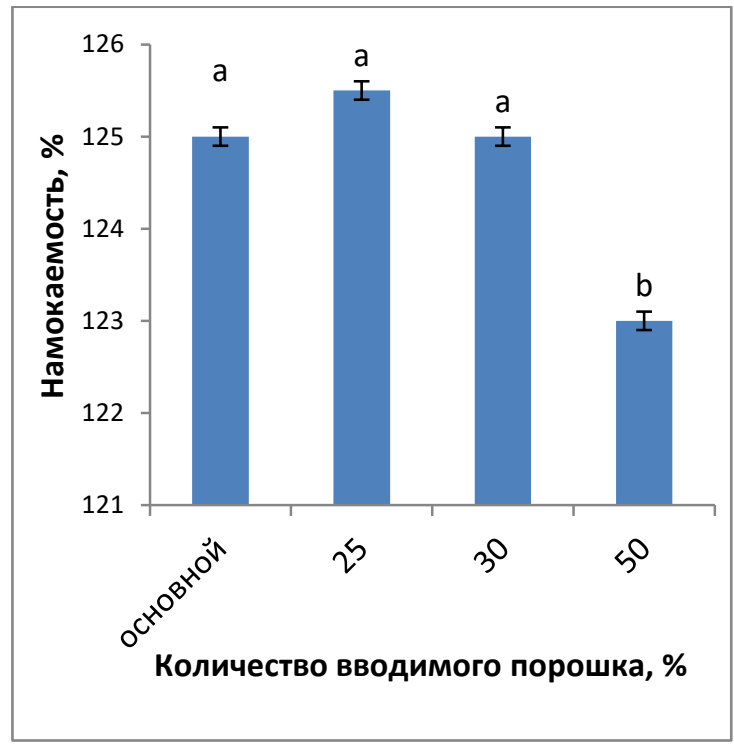

Puс. 6. Изменение намокаемости готовых бисквитов при введении порошка ирги

Такие показатели, как пористость и намокаемость, характеризуют структурно-механические показатели пищевой системы. У изделий с заменой 25-30 \% сахара на порошок данные показатели соответствуют контролю.

Главным критерием качества служила органолептическая оценка. Максимально высокую оценку (10 баллов) получили образцы с заменой 25 и $30 \%$ сахара. Бисквиты имели ровную, блестящую поверхность, мякиш темного цвета с вкраплениями порошка, приятный «черемуховый» вкус, аромат, в меру сладкие, не такие сухие, как традиционный бисквит.
Более высокое содержание порошка (50 \%) формирует невыраженный сладкий вкус, плотную и влажную консистенцию.

Исследовали микробиологическую безопасность новых видов бисквитов на протяжении срока хранения - 72 часов и дополнительно 24 часов.

Одним из способов определения порчи продуктов в период хранения является определение активности воды (Aw). В качестве экспрессметода определения безопасности готовых бисквитов использовали гигрометр Rotonic HygroPalmHP23-AW-Set - прибор для определения активности воды. На рисунке 7 показано изменение активности воды в процессе хранения бисквитов. 


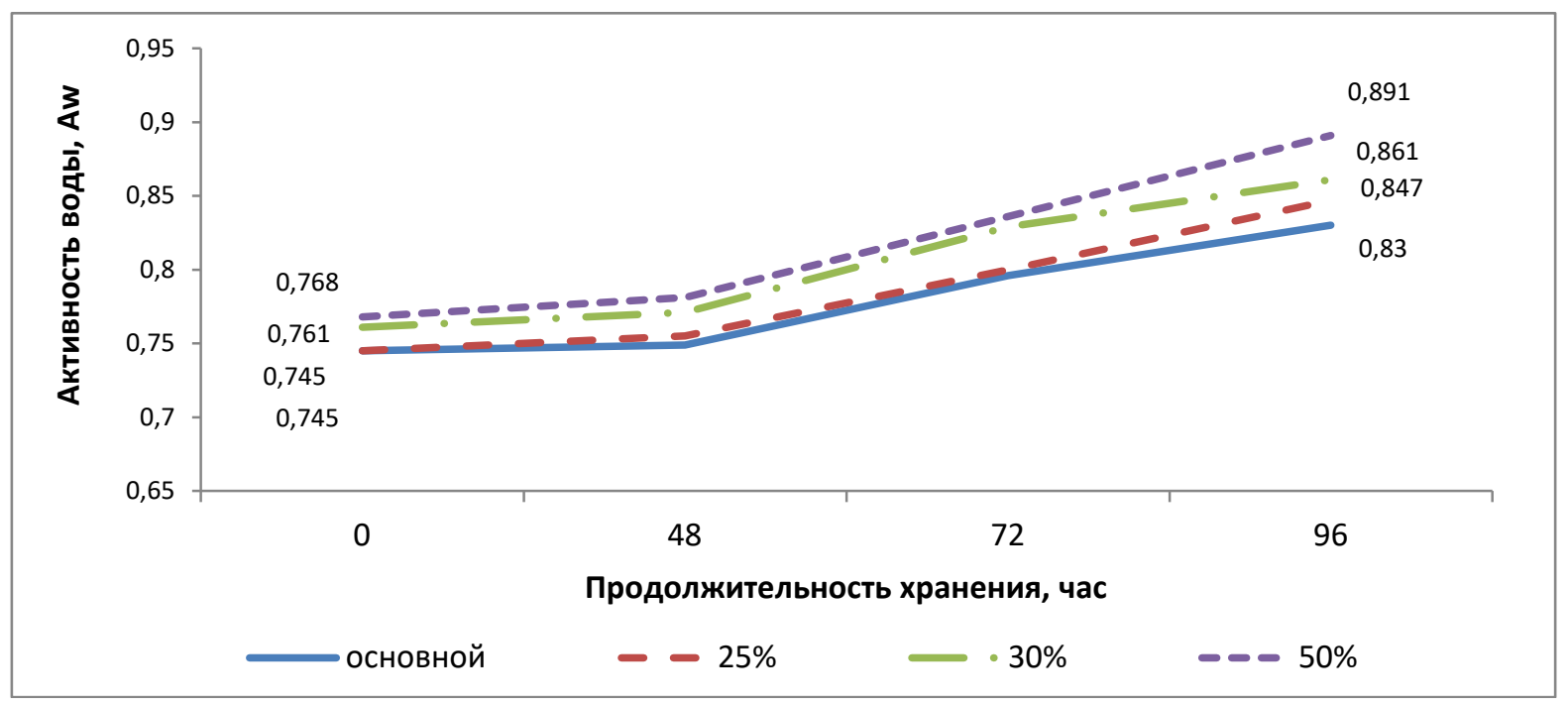

Pис. 7. Изменение активности воды в процессе хранения бисквитов

Большинство бактерий не развиваются при активности воды меньше 0,95, за исключением Staphylococcus aureus и Micrococcus, которые имеют минимальную активность, равную 0,86; а также плесеней и дрожжей с активностью воды $0,88-0,6[6,7]$.

На рисунке 7 видно, что после 72 часов хранения (по нормативным данным) значение Aw не превысило допустимый порог в 0,95 и составило: в контрольном образце $0,796 \pm 0,0003$; в образцах: с заменой $25 \%$ сахара - 0,800 $\pm 0,0001 ;$ с заменой $30 \%-0,829 \pm 0,0003 ;$ с заменой $50 \%$ $0,836 \pm 0,0002$. Увеличение срока хранения до $96 \%$ вызывает развитие плесени только у образца с 50\%-й заменой сахара, что можно объяснить высокой влажностью бисквита.

Таким образом, полученные результаты позволяют говорить о микробиологической безопасности новых видов бисквитов с заменой 25 и $30 \%$ сахара в течение 72 часов хранения.

Выводы. Данные проведенных исследований показали, что по всем основным критериям качества в рецептуре бисквитов возможна замена $30 \%$ сахара на порошок ирги. Калорийность такого бисквита на $12 \%$ ниже по сравнению с контрольным образцом. Кроме этого, в готовом бисквите увеличивается количество минеральных веществ: кальция в 2,5 раза, магния в 2 раза, железа в 1,5 раза.

Новый вид бисквита обладает высокими органолептическими показателями, качественной структурой и может быть рекомендован для всех возрастных категорий населения.

\section{Литература}

1. Васильева С.Б. Товароведная характеристика плодов ирги и продуктов ее переработки: автореф. канд. дис. ... канд. техн. наук: 05.18.15. - Кемерово, 2003. - 19 с.

2. Тесленко Н.Ф. [и др.]. Ягоды ирги как сырье для производства мармелада // Фундаментальные исследования. - 2015. - № 8. С. 333-337.

3. Корячкина С.Я. Новые виды мучных и кондитерских изделий. Научные основы. Технологии. Рецепты. - Орел: Труд, 2006. $460 \mathrm{c}$.

4. Типсина Н.Н. Новые виды кондитерских и хлебобулочных изделий с местным растительным сырьем / Краснояр. гос. агр. ун-т. - Красноярск, 2009. - 260 с.

5. Сборник рецептур мучных кондитерских и булочных изделий. - М.: Экономика, 2000. $295 \mathrm{c}$.

6. Цуканов М.Ф., Черноморец А.Б. Технологические аспекты показателя «активность воды» и его роль в обеспечении качества продукции общественного питания // Технико-технологические проблемы сервиса. 2010. - № 1(11). - С. 58-63.

7. Баранов Б.А. Теоретические и прикладные аспекты показателя «активность воды» в технологии продуктов питания: автореф. дис. ... д-ра техн. наук. - СПб., 2000. 


\section{Literatura}

1. Vasil'eva S.B. Tovarovednaja harakteristika plodov irgi i produktov ee pererabotki: avtoref. kand. dis. ... kand. tehn. nauk: 05.18.15. Kemerovo, 2003. $-19 \mathrm{~s}$.

2. Teslenko N.F. [i dr.]. Jagody irgi kak syr'e dlja proizvodstva marmelada // Fundamental'nye issledovanija. - 2015. - № 8. - S. 333-337.

3. Korjachkina S.Ja. Novye vidy muchnyh i konditerskih izdelij. Nauchnye osnovy. Tehnologii. Recepty. - Orel: Trud, 2006. - 460 s.

4. Tipsina N.N. Novye vidy konditerskih i hlebobulochnyh izdelij s mestnym rastitel'nym syr'em / Krasnojar. gos. agr. un-t. - Krasnoyarsk, 2009. - $260 \mathrm{~s}$.

5. Sbornik receptur muchnyh konditerskih i bulochnyh izdelij. - M.: Jekonomika, 2000. $295 \mathrm{~s}$.

6. Cukanov M.F., Chernomorec A.B. Tehnologicheskie aspekty pokazatelja «aktivnost' vody» i ego rol' v obespechenii kachestva produkcii obshhestvennogo pitanija // Tehnikotehnologicheskie problemy servisa. - 2010. № 1(11). - S. 58-63.

7. Baranov B.A. Teoreticheskie i prikladnye aspekty pokazatelja «aktivnost' vody» V tehnologii produktov pitanija: avtoref. dis. ... d-ra tehn. nauk. - SPb., 2000. 